University of Massachusetts Amherst

ScholarWorks@UMass Amherst

1987

\title{
Flow Manifold for Automated On-Line Dilution of Standards for Flame Atomic Absorption Spectrometry and Its Use in a Null Measurement Method
}

S. R. Bysouth

Loughborough University of Technology

Julian Tyson

University of Massachusetts Amherst

Follow this and additional works at: https://scholarworks.umass.edu/chem_faculty_pubs

Part of the Chemistry Commons

\section{Recommended Citation}

Bysouth, S. R. and Tyson, Julian, "Flow Manifold for Automated On-Line Dilution of Standards for Flame Atomic Absorption Spectrometry and Its Use in a Null Measurement Method" (1987). Journal of Analytical Atomic Spectrometry. 1378.

Retrieved from https://scholarworks.umass.edu/chem_faculty_pubs/1378 


\title{
Flow Manifold for Automated On-line Dilution of Standards for Flame Atomic Absorption Spectrometry and its Use in a Null Measurement Method*
}

\author{
Stephen R. Bysouth and Julian F. Tyson \\ Department of Chemistry, University of Technology, Loughborough, Leicester LE11 3TU, UK
}

\begin{abstract}
A flow manifold that automatically dilutes solutions presented to a flame atomic absorption spectrometer while maintaining a constant flow to the nebuliser is described. The manifold is based on a fixed-speed pump, together with a computer-controlled stream switching valve and pump. The computer is also used for data acquisition and handling. In addition to the production of solutions for a conventional calibration procedure, the system is also used for a novel calibration procedure whereby the stock standard solution is automatically diluted by a known factor until its absorbance matches that of the sample. This null measurement method avoids the need to fit a curve to a set of calibration points. The performance of both methods compares favourably with the conventional procedure with errors ranging from 0.0 to $4 \%$ and no significant bias at the $99 \%$ confidence level. Problems with pulsations in the flow caused by peristaltic pump rollers were encountered with the consequent difficulties of accurate flow-rate measurement. Attempts to improve the speed of the method by the use of flow injection introduction were not successful owing to these pulsations in the flow.
\end{abstract}

Keywords: Automated calibration; flame atomic absorption spectrometry; on-line dilution; null measurement method

The curvature of calibrations in atomic absorption spectrometry (AAS) has been recognised since its conception in 1955.1 The many methods used to compensate for such curvature have developed from manual methods involving plotting calibration points and fitting a curve using a ruler or "flexicurve," through electronic methods that alter the output of the instrument at the turn of a knob, ${ }^{2}$ to computational methods which fit curved mathematical relationships to the response data. ${ }^{3}$ It has been shown that an acceptable analytical performance may be obtained when working in regions where the calibrations are strongly curved. ${ }^{4}$ Hence calibration procedures for the present generation of instrumentation must be capable of dealing with data that fall well outside the linear range. The processes that produce curvature are complex, and instrument manufacturers have produced a variety of model equations for curve fitting. Comparisons of various curve fitting algorithms, including those available for commercial instruments, have been made. 5,6 It was shown that errors as high as $6 \%$ in calculated concentrations were possible. 6 These comparisons also included manual curve fitting methods. As the choice of equation (or equations) for the calibration function is empirical, errors will always occur. Errors due to the curve fitting procedure will only be avoided if an alternative method of calibration is employed.

Null methods, for example, measure the response for a sample and match the response of a standard to it. One null strategy for flame AAS is the method of continuous dilution, 7 where a large array of time - absorbance data is collected by monitoring the exit of a mixing chamber in which a step change in concentration produces a concentration gradient of a known form. The absorbance of a sample is then matched to an array absorbance value and the associated time value is converted to a concentration from the known concentration gradient equation. This method can be considered as a "mix and match" technique, i.e., a very large number of standards are mixed (the concentration gradient) and the sample absorbance is matched to the relevant standard's absorbance.

\footnotetext{
* Presented at the Third Biennial National Atomic Spectroscopy
} Symposium (BNASS), Bristol, UK, 23rd-25th July, 1986.
The method described for flame AAS in this paper is also a "mix and match" technique, but in this instance the standards are mixed iteratively until the standard's absorbance matches that of the sample.

The use of the system for the production of standards for a normal curve fitting calibration is also described.

\section{Apparatus}

\section{Experimental}

The atomic absorption spectrometer, which was either a Baird Atomic A3400 or a Pye Unicam SP9, used an air - acetylene flame. The manifold (Fig. 1) consisted of PTFE tubing of various internal diameters (Radiospares No. 1, Anachem), Y-pieces constructed in our workshops, a fixed speed pump (Ismatec 840), a variable-speed pump (LKB 2132) capable of being computer controlled, a stream-switching valve (Pharmacia) and a computer-controlled injection valve configured for stream switching (P.S. Analytical). An Apple IIe microcomputer was used to monitor the absorbance on an $\mathrm{A} / \mathrm{D}$ convertor (Microcontrol) and to control the pump and valve via an interface built in our own workshops.

\section{Manifold}

Because the response of a flame atomic absorption spectrometer depends on the flow-rate at the nebuliser, 8 the manifold (Fig. 1) was designed to produce a constant flowrate whatever the concentration of standard being mixed.

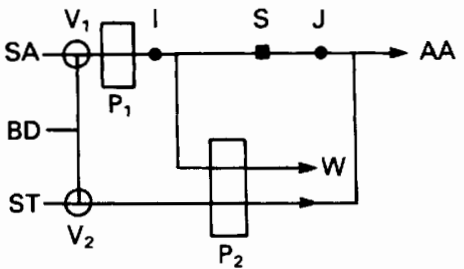

Fig. 1 Diagram of manifold: $P_{1}$, fixed-speed pump; $P_{2}$, computercontrolled pump; $V_{1}$, computer-controlled stream-switching valve; $\mathrm{V}_{2}$, stream-switching valve; $\mathrm{S}$, flow sensor position; 1 and $\mathrm{J}$, injection valve position; AA, spectrometer; SA, sample to be analysed; BD, blank - diluent; ST, stock standard solution; $W$, waste 
During the mixing procedure some of the flow delivered by the constant-speed pump, $P_{1}$, is removed and replaced with flow delivered by the computer-controlled pump, $P_{2}$. By switching the valves the system can be operated in four modes.

(1) Blank: valve $V_{1}$ switched to water and pump $P_{2}$ off.

(2) Sample: valve $V_{1}$ switched to sample and pump $P_{2}$ off.

(3) Diluting sample: valve $V_{1}$ switched to sample, valve $V_{2}$ switched to water and pump $\mathrm{P}_{2}$ on.

(4) Mixing standard: valve $V_{1}$ switched to water, valve $V_{2}$ switched to standard and pump $\mathrm{P}_{2}$ on.

Pump $P_{1}$ was operated at approximately $6 \mathrm{ml} \mathrm{min}^{-1}$, close to the natural aspiration rate of the nebuliser. The maximum flow-rate delivered by pump $\mathrm{P}_{2}$ was approximately 5 $\mathrm{ml} \mathrm{min}^{-1}$. The concentration of the standards produced were calculated from equation (1).

$$
C^{\mathrm{N}}=\frac{C^{\mathrm{S}} \times F \mathrm{~S}}{F^{\mathrm{N}}}
$$

where $C^{\mathrm{N}}$ is the concentration of the standard solution produced, $C^{\mathrm{S}}$ is the concentration of the stock standard solution, $F \mathrm{~s}$ is the flow-rate of the stock standard solution and $F^{\mathrm{N}}$ the flow-rate delivered to the nebuliser. Two methods of measuring the flow-rates were used, namely, (a) the measurement of the time required to pump a known volume from a $10-\mathrm{ml}$ burette and (b) the use of a flow-rate transducer. This consisted of a pressure sensor (Radiospares Type 303-343) which produced a voltage proportional to the differential pressure across a length of tubing that was generated by the flow. When positioned at $S$ in Fig. 1, the transducer monitors the difference in flow-rate between $P_{1}$ and $P_{2}$. The flow delivered by $P_{1}$ may be monitored when $P_{2}$ is switched off. Only preliminary results are reported for this device.

Because of the time taken to wash out the solutions from the pump tubing when the solutions were switched, it was attempted to operate the system in a flow injection mode. The injection valve (Rheodyne Type 5020, manually operated) was positioned at either I or J so that the sample and standard slug $(40 \mu \mathrm{l})$ underwent dilution at the confluence. Pump $\mathrm{P}_{2}$ was not computer controlled and the peaks were monitored on a chart recorder (Pye Unicam PM 8251).

Both pumps produce pulsations in the flow delivered owing to the action of the rollers. These pulsations were worse for the computer-controlled pump at low flow-rates. It is well known that the response of a flame atomic absorption spectrometer is sensitive to the aspiration rate, although usually there is a plateau on the absorbance versus flow-rate response curve slightly above the "normal" aspiration rate. 8 The flow-rate delivered by the fixed-speed pump was therefore chosen to be on the plateau in order that pulses in the flow-rate did not affect the absorbance response. The combination of pulsations from both pumps produces variations in the concentration at the nebuliser owing to uneven mixing of the standards.

The resulting variation in absorbance is worst at low concentrations when the computer-controlled pump (driven by a stepper motor) is rotating slowly. At an average signal level of 0.05 absorbance the pulsations produce excursions of as much as 0.02 absorbance. The bore of the pump tubing, speed of rotation and number of rollers are such as to produce 63.9 pulses $\min ^{-1}$ per $\mathrm{ml} \mathrm{min}^{-1}$. As the flow-rate delivered by this pump is known from the calibration experiment, and the data are collected at the rate of 45 points $\mathrm{s}^{-1}$, the number of data points corresponding to one roller pulse may be calculated. In order to compensate for concentration fluctuations the measured absorbance is averaged over enough readings for two roller pulses plus a further 200 .

An alternative manifold configuration would involve the pumping of the standard by the fixed-speed pump and the diluent by the computer-controlled pump. The pronounced pulsing at low speeds for this latter pump causes errors in the mean absorbance value for a mixed standard. The concentration oscillates symmetrically about the desired value but, because at higher concentrations there is a non-linear relationship between absorbance and concentration, the absorbance does not oscillate about the value corresponding to the mean concentration value. In the configuration used (standard delivered by variable-speed pump, diluent by fixed-speed pump), the worst pulsations, and hence oscillations in concentration, are produced at low concentrations where there is a linear relationship between the absorbance and the concentration. This configuration also has the advantages of (a) conserving the standard (none goes to waste) and (b) making the measurement of the blank straightforward.

\section{Solutions}

Working solutions were prepared by dilution of stock 1000 mg $1^{-1}$ solutions (BDH Chemicals) of the appropriate element. Magnesium was used for the flow injection experiments and chromium for the steady-state dilution experiments. Chromium was chosen as its calibration displays both linear and curved portions over the normal working range.

\section{Programs and Operation}

The programs were written in BASIC and operated in the following manner.

\section{Mix and match}

Both pumps are calibrated with respect to flow-rate as described. The top standard, of known concentration calculated from equation (1), is then mixed by running pump $\mathrm{P}_{2}$ at its maximum rate and the absorbance is measured. The blank absorbance is then measured. Valve $\mathrm{V}_{1}$ is switched automatically and the absorbance of a sample measured. If its absorbance is higher than that of the top standard, the sample is diluted by pumping water, via pump $\mathrm{P}_{2}$ at its maximum pumping rate, into the sample. If the sample is still too concentrated, no further dilution is possible and the program informs the operator that the sample is too concentrated.

Assuming that the sample absorbance can be brought into range, an initial estimate of the sample concentration is obtained by assuming a linear concentration - absorbance relationship. A standard of this concentration is then mixed by returning valve $V_{1}$ to water and pumping the standard solution at the appropriate rate, and the absorbance is measured. For a convex calibration curve, the concentration estimated will be found to give too high an absorbance (Fig. 2). Using the values of concentration and absorbance obtained for the new standard as replacements for the values for the highest standard, a new estimate of sample concentration is calculated, mixed and measured as before. This process is repeated until the absorbances of the standard and sample are within $2 \%$. The iteration then stops and the concentration of the standard is displayed. If the sample has been diluted, multiplication by the dilution factor gives the concentration of the sample.

If the number of iterations necessary to find a match is greater than five, the procedure stops and re-samples. This helps to correct for drift during iterations and stops the system oscillating about the sample concentration. Before resampling or measuring a new sample, the blank is measured.

During the iteration procedure the concentration and absorbance data obtained from each standard mixed is collected in an array. This array covers the range from zero to the highest standard concentration and is divided into 21 pairs of elements. Each pair of elements stores a concentration and an absorbance value covering $1 / 21$ of the calibration range. Thus the concentration axis is divided into 20 contiguous segments. When a concentration falling within a particular segment has been mixed and its absorbance measured to 
determine the concentration, the absorbance values are entered into the appropriate pair of elements in the array. Thus, a set of calibration data is accumulated corresponding to 20 (somewhat irregularly spaced) standards. After the first sample has been analysed some values will have been entered into the array, so the initial concentration estimate of subsequent samples is calculated by starting from the entry in the array that has an absorbance of $7 \%$ or higher than that of the sample. The $7 \%$ difference was chosen as a compromise between finding a match immediately and a large number of iterations. During subsequent analyses, the concentration and absorbance values in the array are continually updated.

\section{Conventional curve fitting calibration}

The flow-rates delivered by the pumps are calibrated as described and ten standards are mixed by the pumping standard at ten incremental speeds, up to the highest standard concentration. The rational function (equation 2 ) is fitted by the method of least squares:

$$
A / C=a+b A+c A^{2}
$$

where $A$ is the absorbance, $C$ is the concentration and $a, b$ and $c$ are constants to be found during the least-squares calculation. This equation, used by Baird-Atomic in the Alphastar system, ${ }^{3}$ was found to give good results in a comparison of curve fitting methods. 6

Ten samples are then analysed and then the system re-calibrates by mixing ten new standards, curve fitting, etc.

\section{Evaluation of manifold performance}

For pump calibration by burette and stop-watch, the stock concentration of $\mathrm{Cr}$ was $80 \mathrm{mg} \mathrm{l}^{-1}$. Solutions of concentrations over the range $2-100 \mathrm{mg}^{-1}$ were analysed by the mix and match method. With the flow-rate measured by the pressure transducer, the stock concentration was $50 \mathrm{mg} \mathrm{l}^{-1}$ of $\mathrm{Cr}$ and solutions covering the range $5-25 \mathrm{mg} \mathrm{l}^{-1}$ were analysed by both the mix and match method and the conventional curve fitting method.

For the flow injection manifold solutions of $0.5,1.0$ and 2.0 $\mathrm{mg} \mathrm{l}^{-1}$ of magnesium were used. Each solution was injected and the flows were adjusted to try to dilute the slug to produce the lower concentrations. The peak heights were then compared.

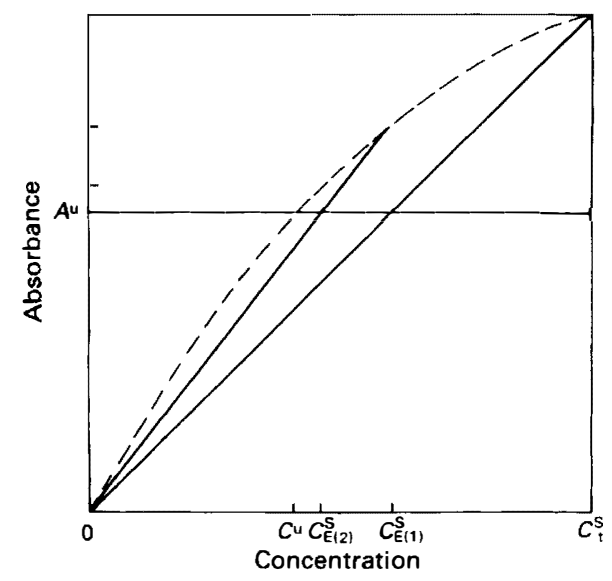

Fig. 2. Basic principle of mix and match method. The broken line is the absorbance - concentration relationship. The absorbance of the unknown, $A^{\text {u }}$, is measured. A linear absorbance - concentration relationship is assumed between the highest standard, $C_{t}^{S}$ and the blank producing the first estimate for the concentration of the unknown, $C$ u of $C_{\mathrm{E}_{(1)}}^{\mathrm{S}}$. This concentration is mixed and introduced into the spectrometer and the process repeated thus gives rise to the second estimate for $C$ u of $C_{\mathrm{E}(2)}^{\mathrm{S}}$. This continues until the absorbance of $C_{\mathrm{E}(n)}^{\mathrm{s}}$ is within $2 \%$ of $A^{\mathrm{u}}$

\section{Results and Discussion}

The results for the mix and match chromium determination with burette pump calibration are presented in Table 1 . The results represent three replicate analyses. Each final value resulted after less than four iterations. The means appear to indicate some bias, although this is only significant at the $95 \%$ confidence level for one result. The errors in concentration range from 0.50 to $4.1 \%$ and are comparable to the errors obtained with normal curve fitting methods. ${ }^{6}$ Apart from the $2.00 \mathrm{mg} \mathrm{l}^{-1}$ solution, the relative standard deviations are all less than $1 \%$.

When the values in the second column are pooled on a percentage recovery basis the mean value is $101.7 \%$ and the $95 \%$ confidence interval is $\pm 1.2 \%$. Thus a bias at this level of confidence is indicated. The $99 \%$ confidence interval is $\pm 1.7 \%$. If the three results obtained for the nominal $10 \mathrm{mg} \mathrm{l}^{-1}$ solution are omitted, the $95 \%$ confidence interval becomes $101.1 \pm 1.4 \%$ and no bias is indicated. It was noticed that the method did not always approach the nominal value from the "high side" for the final iteration, but it is possible that starting the iterations from the high side produces a bias. Further work is required (a) to establish whether the method is biased and (b) to discover what the causes of any bias are.

The program reads the base line before sampling and then matches a standard; hence any drift is compensated for, unless it occurs between reading the sample and finding a standard match. As some time is required for the peristaltic pump tubing to wash through with the various solutions when the valves are switched, the system is slow, taking about $1.5 \mathrm{~min}$ to analyse a sample. This time also depends on the number of iterations and whether the sample needs diluting.

In an attempt to speed up the process, sample introduction by flow injection was performed. However, the precision of the resulting peak heights were very poor and the method

Table 1. Results of mix and match method for the determination of chromium. Pump calibration by timed delivery from a burette

\begin{tabular}{|c|c|c|c|c|c|}
\hline $\begin{array}{l}\text { Nominal } \\
\text { concen- } \\
\text { tration/ } \\
\mathrm{mg} \mathrm{l}^{-1}\end{array}$ & $\begin{array}{l}\text { Calculated } \\
\text { concen- } \\
\text { tration/ } \\
\mathrm{mg} \mathrm{l}^{-1}\end{array}$ & $\begin{array}{l}\text { Mean } \\
\text { concen- } \\
\text { tration/ } \\
\mathrm{mg} \mathrm{1}^{-1}\end{array}$ & $\begin{array}{c}\text { Standard } \\
\text { devia- } \\
\text { tion/ } \\
\text { mg l-1 }^{-1}\end{array}$ & $\begin{array}{l}\text { Relative } \\
\text { standard } \\
\text { devia- } \\
\text { tion, } \%\end{array}$ & $\begin{array}{l}95 \% \\
\text { confid- } \\
\text { ence } \\
\text { interval/ } \\
\mathrm{mg} \mathrm{l}^{-1}\end{array}$ \\
\hline $\begin{array}{l}2.00 \\
5.00\end{array}$ & $2.11,1.93,1.99$ & 2.01 & 0.092 & 4.6 & $\begin{array}{l}0.23 \\
0.11\end{array}$ \\
\hline 10.00 & $10.46,10.39,10.38$ & $\begin{array}{r}J .00 \\
10.41\end{array}$ & $\begin{array}{l}0.043 \\
0.044\end{array}$ & 0.4 & 0.11 \\
\hline 15.00 & $15.00,15.16,15.09$ & 15.08 & 0.080 & 0 & 0.20 \\
\hline 20.00 & $20.21,20.53,20.38$ & 20.37 & 0.16 & 0.79 & 0.40 \\
\hline
\end{tabular}

Table 2. Mix and match method with flow-rate pump calibration using the flow-rate transducer for the determination of chromium

$\begin{array}{cc}\begin{array}{c}\text { Sample } \\ \text { concentration/ } \\ \mathrm{mg} \mathrm{l}^{-1}\end{array} & \begin{array}{c}\text { Calculated } \\ \text { concentration/ } \\ \mathrm{mg} \mathrm{I}^{-1}\end{array} \\ 5.00 & 5.30 \\ 10.0 & 10.4 \\ 25.0 & 25.3\end{array}$

Table 3. Results for curve fitting calibration determination of chromium. Pump calibration by timed delivery from a burette

\begin{tabular}{cccccc}
$\begin{array}{c}\text { Nominal } \\
\text { concen- } \\
\text { tration/ } \\
\mathrm{mg} \mathrm{I}^{-1}\end{array}$ & $\begin{array}{c}\text { Mean } \\
\text { concen- } \\
\text { tration } \\
\text { found/ } \\
\mathrm{mg} \mathrm{I}^{-1}\end{array}$ & $\begin{array}{c}\text { Standard } \\
\text { deviation/ } / \\
\mathrm{mg} \mathrm{I}^{-1}\end{array}$ & $\begin{array}{c}\text { Relative } \\
\text { standard } \\
\text { deviation, } \\
\text { \% }\end{array}$ & $\begin{array}{c}95 \% \\
\text { confidence } \\
\text { interval/ } \\
\mathrm{mg} \mathrm{l}^{-1}\end{array}$ & $\begin{array}{c}\text { Number of } \\
\text { replicates }\end{array}$ \\
10.00 & 5.14 & 0.32 & 6.2 & 0.30 & 7 \\
15.00 & 9.84 & 0.31 & 3.2 & 0.16 & 16 \\
25.00 & 15.00 & 0.44 & 2.9 & 0.37 & 8 \\
\hline
\end{tabular}


proved to be extremely inaccurate. This was probably due to the pump pulsations giving rise to a varying dilution of the slug.

Some preliminary results are presented in Table 2 for the determination of chromium using the mix and match technique with the second method of pump calibration (use of flow-rate transducer). Owing to the difficulty in reading the flow-rate directly from the transducer when the pumps are pulsing, the output was monitored using a chart recorder and the estimated mean value entered into the computer. Because the net result of the pump pulsations is not sinusoidal, estimating the mean value will be a source of error in the flow-rate calibration.

Results for the curve fitting calibration are presented in Table 3. The results are averaged over four calibrations. The best fit of equation (2) to the data gave correlation coefficients of $0.9937,0.9955,0.9958$ and 0.9916 . The errors range from 0.0 to $2.8 \%$ with no significant bias at the $95 \%$ confidence level. However, the relative standard deviations are poorer than the mix and match method and probably worse than would be expected from conventional calibrations. However few data are available for the latter instance, the precision of the technique normally being quoted in terms of the relative standard deviation of the instrument response.

Preliminary results indicate that the manifold can probably be used for the on-line dilution of the sample in instances when this is above the normal concentration range. Further work is necessary to characterise fully the performance of the manifold in this mode of operation.

\section{Conclusions}

A flow manifold for the automated on-line dilution of standards while maintaining a constant flow to the atomic absorption spectrometer has been shown to perform little worse than the more conventional use of volumetric apparatus. The feasibility of a novel method of analysis in which there is no calibration (in the conventional sense) has been demonstrated. This mix and match method shows errors only marginally worse than those arising from fitting a curve through a set of calibration points. Unlike the conventional curve fitting procedure, the accuracy of which depends on the shape of the curve, which in turn depends on the element being determined, the mix and match procedure should be free from such element-related effects.
One of the major sources of error in this method arises from the use of relatively inexpensive peristaltic pumps, which produce pulsations in the flow. This source of error could no doubt be minimised by the use of more expensive HPLC-type pumps. Good quality pumps of this type may also eliminate another major source of error in the system, namely the requirement to measure flow-rate accurately, as delivery rates may be reliably pre-set.

Once pulsations in the system are removed, flow injection sample and standard introduction would be feasible with a consequent increase in the speed of the over-all procedure. However, the consequent increase in cost of such a system may well prevent it from being a serious contender as a practical alternative sample introduction strategy.

The manifold has a number of other features, as yet not investigated to any great extent. It could be used to create a variety of concentration gradients and use of the system is not limited to flame atomic absorption spectrometry; it could be used for any analytical instrument with a flow-through detector capacity.

If real samples were to be analysed in which known interferents were present, the stock standard and the blank diluent could be matrix-matched to the samples.

The authors thank the Trustees of the Analytical Chemistry Trust Fund of the Royal Society of Chemistry for the award of an SAC Research Studentship.

\section{References}

1. Walsh, A., Spectrochim. Acta, Part B, 1955, 7, 108.

2. "SP 90 Series 2 Technical Manual," Pye Unicam, Cambridge, 1974 , p. 4.10.

3. Tyson, J. F., Analyst, 1984, 109, 313.

4. de Galan, L., van Dalen, H. P. J., and Kornblum, G. R., Analyst, 1985, 110, 323.

5. Miller-Ihli, N. J., O'Haver, T. C., and Harnly, J. M., Spectrochim. Acta, Part B, 1984, 39, 1603.

6. Bysouth, S. R., and Tyson, J. F., J. Anal. At. Spectrom., 1986, 1,85 .

7. Tyson, J. F., and Appleton, J. M. H., Anal. Proc., 1985, 22, 17.

8. Tyson, J. F., Adeeyinwo, C. E., Appleton, J. M. H., Bysouth, S. R., Idris, A. B., and Sarkissian, L. L., Analyst, 1985, 110, 487.

Paper J6/72

Received August 12th, 1986 Accepted November 12th, 1986 